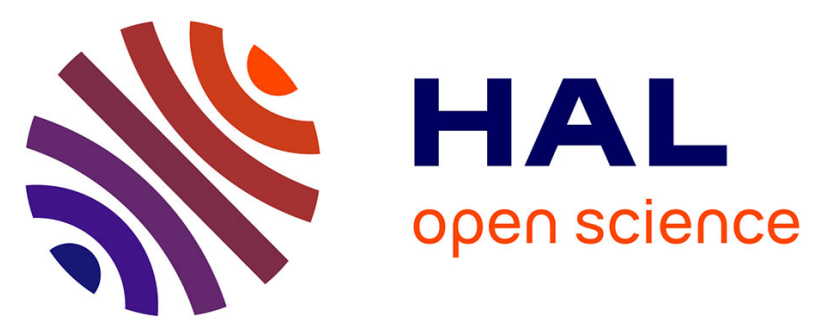

\title{
Respective roles of organic and mineral components of human cortical bone matrix in micromechanical behavior: An instrumented indentation study
} Yohann Bala, Thierry Douillard, P. Clement, Sylvain Meille, Baptiste Dépalle, Hélène Follet, Jérome Chevalier, Georges Boivin

\section{To cite this version:}

Yohann Bala, Thierry Douillard, P. Clement, Sylvain Meille, Baptiste Dépalle, et al.. Respective roles of organic and mineral components of human cortical bone matrix in micromechanical behavior: An instrumented indentation study. Journal of the mechanical behavior of biomedical materials, 2011,4 (7), pp.1473-1482. 10.1016/j.jmbbm.2011.05.017 . hal-01183693

\section{HAL Id: hal-01183693 \\ https://hal.science/hal-01183693}

Submitted on 6 Nov 2019

HAL is a multi-disciplinary open access archive for the deposit and dissemination of scientific research documents, whether they are published or not. The documents may come from teaching and research institutions in France or abroad, or from public or private research centers.
L'archive ouverte pluridisciplinaire HAL, est destinée au dépôt et à la diffusion de documents scientifiques de niveau recherche, publiés ou non, émanant des établissements d'enseignement et de recherche français ou étrangers, des laboratoires publics ou privés. 
Provided for non-commercial research and education use. Not for reproduction, distribution or commercial use.

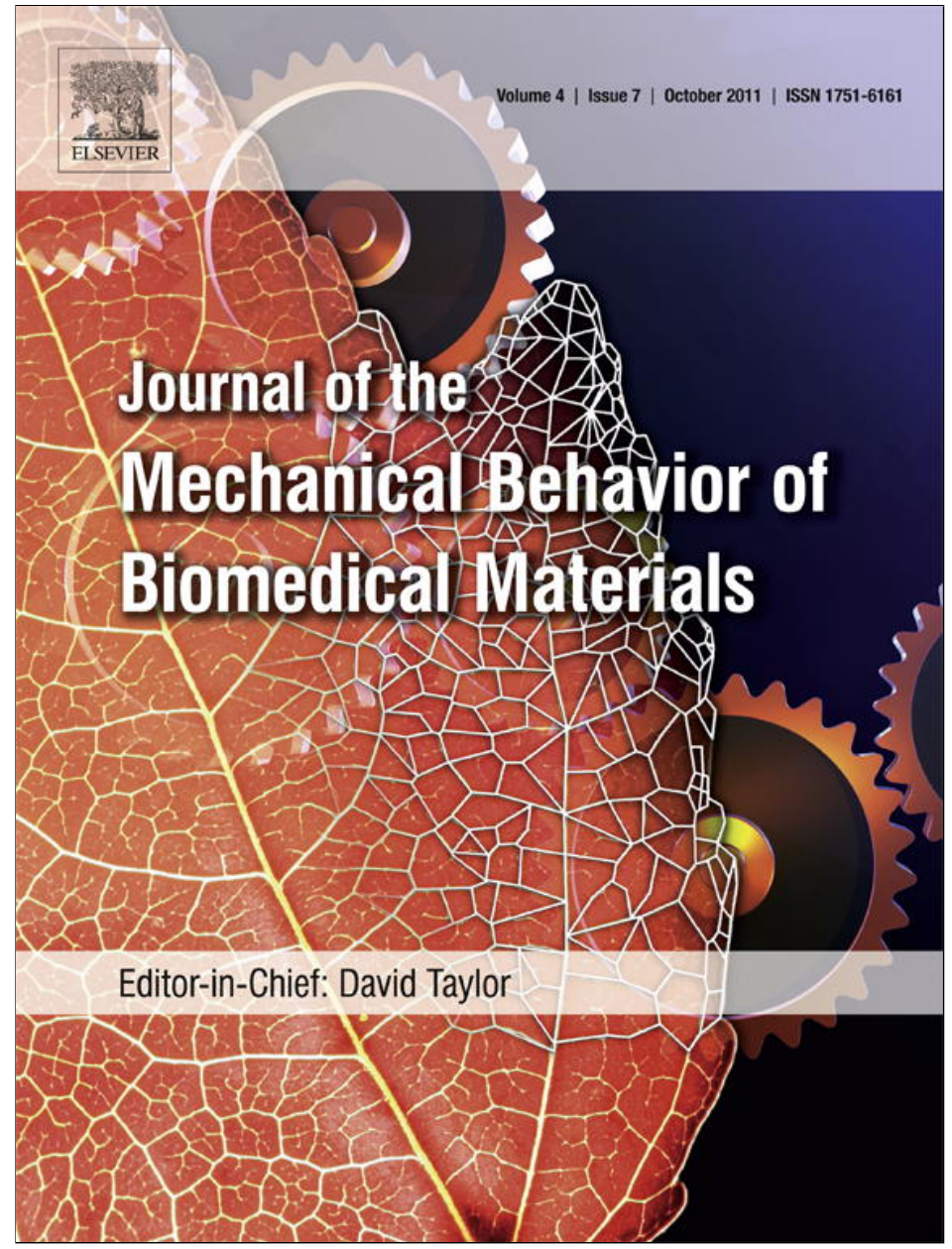

This article appeared in a journal published by Elsevier. The attached copy is furnished to the author for internal non-commercial research and education use, including for instruction at the authors institution and sharing with colleagues.

Other uses, including reproduction and distribution, or selling or licensing copies, or posting to personal, institutional or third party websites are prohibited.

In most cases authors are permitted to post their version of the article (e.g. in Word or Tex form) to their personal website or institutional repository. Authors requiring further information regarding Elsevier's archiving and manuscript policies are encouraged to visit:

http://www.elsevier.com/copyright 
Research paper

\title{
Respective roles of organic and mineral components of human cortical bone matrix in micromechanical behavior: An instrumented indentation study
}

\author{
Y. Bala ${ }^{a, b, c, *, 1}$, B. Depalle ${ }^{a, b, c, 1}$, T. Douillard ${ }^{d}$, S. Meille ${ }^{d}$, P. Clément $^{d}$, H. Follet $^{a, b, c}$, \\ J. Chevalier ${ }^{d}$, G. Boivin ${ }^{a}$ \\ a INSERM, UMR1033, F-69008, Lyon, France \\ ${ }^{\mathrm{b}}$ Université de Lyon, Lyon, France \\ ${ }^{c}$ Hospices Civils de Lyon, France \\ d Université de Lyon, INSA-Lyon, MATEIS, CNRS UMR 5510, F-69621, Villeurbanne, France
}

A R T I C L E I N F O

Article history:

Received 8 March 2011

Received in revised form

14 April 2011

Accepted 7 May 2011

Published online 17 May 2011

Keywords:

Human cortical bone

Mineralization

Indentation

Hardness

Collagen maturity

\begin{abstract}
A B S T R A C T
Bone is a multiscale composite material made of both a type I collagen matrix and a poorly crystalline apatite mineral phase. Due to remodeling activity, cortical bone is made of Bone Structural Units (BSUs) called osteons. Since osteon represents a fundamental level of structural hierarchy, it is important to investigate the relationship between mechanical behavior and tissue composition at this scale for a better understanding of the mechanisms of bone fragility. The aim of this study is to analyze the links between ultrastructural properties and the mechanical behavior of bone tissue at the scale of osteon.

Iliac bone biopsies were taken from untreated postmenopausal osteoporotic women, embedded, sectioned and microradiographed to assess the degree of mineralization of bone (DMB). On each section, BSUs of known DMB were indented with relatively high load $(\sim 500 \mathrm{mN})$ to determine local elastic modulus $(E)$, contact hardness $\left(H_{C}\right)$ and true hardness $(H)$ of several bone lamellae. Crystallinity and collagen maturity were measured by Fourier Transform InfraRed Microspectroscopy (FTIRM) on the same BSUs. Inter-relationships between mechanical properties and ultrastructural components were analyzed using multiple regression analysis.

This study showed that elastic deformation was only explained by DMB whereas plastic deformation was more correlated with collagen maturity. Contact hardness, reflecting both elastic and plastic behaviors, was correlated with both DMB and collagen maturity. No relationship was found between crystallinity and mechanical properties at the osteon level.
\end{abstract}

(c) 2011 Elsevier Ltd. All rights reserved.

\footnotetext{
* Corresponding address: INSERM UMR 1033 Equipe "Qualité Osseuse et Marqueurs Biologiques", Université de Lyon, Faculté de Médecine Lyon Est, Claude Bernard (Domaine Laennec), 7-11 rue Guillaume Paradin, 69372 Lyon Cedex 08, France. Tel.: +33 478785735 ; fax: +33 4 78778663.

E-mail addresses: yohannbala@gmail.com, yohann.bala@univ-lyon1.fr (Y. Bala).

1 The first two authors contributed equally to this work. 1751-6161/\$ - see front matter (c) 2011 Elsevier Ltd. All rights reserved. doi:10.1016/j.jmbbm.2011.05.017
} 
Introduction

Bone is a living multiscale composite material made of an organic matrix (organized network of type I collagen fibrils) filled with a mineral component (apatite crystals bound to the collagen fibrils) (Rho et al., 1998). Bone tissue is in a continuous remodeling process consisting in a succession of resorption and formation phases. This process intends to repair the microdamaged matrix, to adapt the microarchitecture to the mechanical environment, and to regulate calcium homeostasis (Cowin, 2001; Hadjidakis and Androulakis, 2006). At the microscopic scale in cortical bone, remodeling leads to the formation of osteons, tubular microstructures ranging from 10 to $500 \mu \mathrm{m}$ in diameter and about $2.5 \mathrm{~mm}$ in length (Cowin, 2001). Osteons are made of 5 to 30 concentric lamellae with different collagen fibrils orientations (Ascenzi and Bonucci, 1968) and arranged around Haversian canals ensuring blood supply and innervation of bone. Osteons are oriented in the same direction, along the diaphysis in long bones, and separated by interstitial bone tissue that is made up of former partially remodeled osteons. Both osteons and interstitial bone represent Bone Structural Units (BSUs). Depending mainly on time since deposition, each mature BSU has a fairly uniform mineral content (Hadjidakis and Androulakis, 2006). The mineral content is considered to play a major role in bone strength (Boivin et al., 2008; Follet et al., 2004; Roschger et al., 2008). The role of collagen component remains barely known and it may play a role in plastic deformation (Currey, 2003).

Indentation techniques have been widely used to study bone tissue micromechanical properties. Since the early 1950's, it has been demonstrated that osteon microhardness was strongly related to its mineral content (Amprino, 1958; Carlstrom, 1954; Weaver, 1966). These pioneering works suggested that indentation was a relevant methodology for bone tissue mechanical behavior assessment. The results found in these initial studies have been confirmed many times on cortical and trabecular bone from various animal models as well as human bone (Bala et al., 2010; Boivin et al., 2008; Hodgskinson et al., 1989). However, interpreting microhardness values is complicated because this parameter is related to both elastic and plastic deformations (Evans et al., 1990).

In the early 1990's, Oliver and Pharr (1992) developed an innovative technique to measure directly, on small indented areas, both elastic modulus $(E)$ and contact hardness $\left(\mathrm{H}_{\mathrm{C}}\right)$. Contact Hardness corresponds to the ratio between indentation load and the contact area of the indentation print. The determination of $H_{C}$ is easy, and $H_{C}$ is often used in materials science to characterize the resistance to surface damage. However, indentation leads to elasto-plastic deformations and $\mathrm{H}_{\mathrm{C}}$ is therefore related to both elastic and plastic properties of a given material. In the case of bone, the authors found that $H_{C}$ was linearly dependent on $\mathrm{E}$ (Ferguson, 2009; Oyen, 2006; Smith et al., 2010). Therefore $H_{c}$ cannot be used to distinguish and characterize only the plastic behavior of the material.

More recently, Sakai (1999) has analyzed the explicit interdependence between $H_{C}$ and $E$ by assuming an in-series two-element mechanical model to dissociate elastic and plastic contributions to deformation. He developed a method to calculate a variable reflecting exclusively the resistance to plastic deformations, called true hardness (H) (Oyen, 2006; Sakai, 1999). Using this approach in bone, $E$ and $H$ were moderately or not correlated (Smith et al., 2010). E, $H_{C}$ and $H$ are strongly influenced by the amount of mineral but their link to the organic matrix remains unclear.

Very few studies have specifically investigated the role of crystallinity in the mechanical behavior of bone. Vibrational spectroscopies such as Raman or Fourier Transform InfraRed Microspectroscopy (FTIRM) are valuable tools to assess mineral properties in terms of crystallinity (i.e., crystal size/strain) and maturity ("age" of crystals) (Carden and Morris, 2000; Farlay et al., 2010). Such methodologies have also been used to characterize parameters reflecting the collagen properties which seem to be responsible for the viscous micromechanical properties (Isaksson et al., 2010; Paschalis et al., 1996).

To understand the mechanical properties of bone material, and the mechanisms involved in bone fragility (Osteoporosis), it is important to study the mechanical properties of its different components, and the relationships between them at the various levels of hierarchical structural organization (Landis, 1995; Rho et al., 1998). Osteon being the BSU of cortical bone, it represents a major level of cortical structure at which the relationship between mechanical competence and composition needs to be investigated. The aim of the present study is to determine the impact of multiscale determinants of mineral and organic components in micromechanical behavior of osteoporotic human iliac cortical bone tissue. Thus, using an innovative experimental set up, we measured elastic and plastic behavior of bone tissue ( $E$ and $H$, respectively) and bone ultrastructural properties (degree of mineralization, mineral crystallinity and maturity of collagen) in the same BSUs. Two main hypotheses were tested: First, the degree of mineralization is a major determinant of both elastic and plastic deformation; second, crystallinity, reflecting mineral quality, and collagen maturity also have a significant impact on micromechanical behavior.

\section{Material and methods}

\subsection{Iliac bone samples}

Five transiliac bone samples taken from $69 \pm 2$ year-old postmenopausal osteoporotic women were used. Osteoporosis was defined as a lumbar and/or hip bone mineral density of at least -2.5 standard deviations below the mean for young adult or at least two moderate ( $>25 \%$ vertebral height loss) vertebral fractures. Undecalcified samples were fixed in $70 \%$ alcohol, dehydrated in absolute alcohol, and then embedded in methyl methacrylate (MMA). For quantitative microradiography, $150 \mu \mathrm{m}$-thick sections were cut, in a perpendicular plan to the Haversian canals with a precision diamond wire saw (Well, Escil, Chassieu, France). Sections were progressively ground (silicium carbides) to a thickness of $100 \pm 1 \mu \mathrm{m}$ and polished with a diamond suspension $(0.25 \mu \mathrm{m})$ (Boivin and Meunier, 2002). These sections were microradiographed, indented and then re-sectioned into $2 \mu \mathrm{m}$-thick sections for infrared spectroscopy using a Polycut E microtome (Leica, Wetzlar, Germany). 


\subsection{Quantitative microradiography (Boivin et al., 2008)}

Contact microradiography of $100 \mu \mathrm{m}$-thick bone sections was performed to assess the degree of mineralization of bone (DMB) using an X-ray diffraction unit PW 1830/40 (Philips, Limeil Brévannes, France). The nickel-filtered copper $\mathrm{K} \alpha$ radiation was used under $25 \mathrm{kV}$ and $25 \mathrm{~mA}$. Both bone sample and an aluminum standard X-ray absorption was recorded on a high-resolution film exposed for $20 \mathrm{~min}$ (Geola, Slavich International Wholesale Office, Vilnius, Lithuania). Acquisitions of microradiographs were performed with a digital camera (image pixel size: $5.64 \mu \mathrm{m}$ ). After calibration using the aluminum standard, the mean gray level of BSUs were converted into degree of mineralization values (in $\mathrm{g}$ mineral $/ \mathrm{cm}^{3}$ ). From the microradiographs of the 5 bone samples, a total of 150 BSUs (osteons and interstitial areas) were selected and analyzed to obtain the largest range of DMB values.

\subsection{Instrumented indentation testing}

Nanoindentation tests were carried out using a Nano Indenter II machine (Nano Instruments Inc., USA) equipped with a Berkovich diamond tip. Indentation tests were performed under displacement control according the following protocol: A $0.05 \mathrm{~s}^{-1}$ constant strain rate was applied to a peak of displacement of $5000 \mathrm{~nm}$, followed by a $10 \mathrm{~s}$ dwell at peak displacement to limit the viscous behavior of bone tissue, a $45 \mathrm{~s}$ withdrawal to $10 \%$ of maximum displacement, a $50-\mathrm{s}$ hold period for thermal drift calculation and final withdrawal to zero displacement (Fig. 1). The measurements were done at relatively high load $(\sim 500 \mathrm{mN})$ to overcome the effects related to the heterogeneity of bone tissue at lamellar level and in Continuous Stiffness Mode (CSM), to measure the mechanical properties continuously along the depth of the sample and assure the homogeneity of bone tissue. The system was calibrated with fused silica according Oliver and Pharr (1992) protocol. The 150 BSUs selected for DMB measurements were indented. The indent location was chosen at sites distant from visible lacunae or other discontinuities.

\subsection{Indentation analysis}

Indentation curves were analyzed using a homemade program developed with Matlab R2010a (The MathWorks Inc., Natik MA, USA). For each indent, elastic modulus, $E$ and contact hardness, $\mathrm{H}_{\mathrm{C}}$ were calculated according the method described by Oliver and Pharr (1992). Assuming bone as an isotropic material, the elastic modulus was calculated from the following equation:

$\frac{1}{E_{r}}=\frac{1-v^{2}}{E}+\frac{1-v^{2}}{E_{i}}$

where $E_{i}$ and $v_{i}$ are the elastic modulus and Poisson's ratio of the diamond indenter (1140 GPa and 0.07 respectively). For isotropic models, the Poisson modulus of bone $v$ is usually assumed to be 0.3 (Zysset et al., 1999). $E_{r}$ is the reduced modulus, calculated using the formula:

$E_{r}=\frac{S \sqrt{\pi}}{2 \beta \sqrt{A}}$

where $\mathrm{A}$ is the projected contact area, $\beta$ is an empirical indenter shape factor Berkovich tip (1.034) and $S$ the stiffness of the sample derived from the initial tangent of the

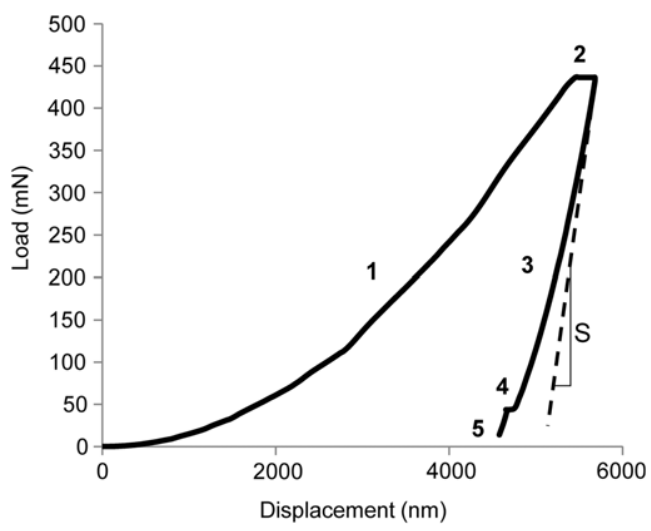

Fig. 1 - Typical load-depth curve obtained with indentation testing. The curve shows regions related to loading (1), $10 \mathrm{~s}$ holding segment (2), $90 \%$ unloading (3), 50 s holding segment allowing the thermal drift correction (4) and complete unloading (5). $S$ is the contact stiffness corresponding to the slope of the unloading curve tangent.

unloading segment of the load/depth curve. The stiffness was calculated from a power fit to the unloading curve. The regression was performed with a Levenberg-Marquardt algorithm. Contact hardness was calculated from the equation:

$H_{C}=\frac{P_{\max }}{A}$

where $P_{\max }$ is the maximum load. The values of $E$ and $H_{C}$ given by Oliver and Pharr method were highly correlated. Based on the Sakai model, Oyen and Cook dissociate elastic and plastic deformations in mineralized tissue (Oyen, 2006; Oyen and Cook, 2003; Sakai, 1999). In this model, bone is considered to be an elasto-plastic material and its mechanical behavior during loading of the indentation test is modeled as a purely elastic element connected to a purely plastic element in series in a sense of the Maxwell combination. The elastic element is characterized by the elastic modulus $E$, and the plastic one by the true hardness $H$. Developing the constitutive relationships for pyramidal indentation for both components allow to derive $H_{C}$ as a function of $E$ and $H$ (Sakai, 1999):

$H_{C}=\frac{1}{\alpha_{1}\left(\left(\alpha_{2} E^{*}\right)^{-1 / 2}+\left(\alpha_{1} H\right)^{-1 / 2}\right)^{2}}$

where $\alpha_{1}=24.5$ and $\alpha_{2}=4.4$ are adimensional constants associated with Berkovich indentation tip and $E^{*}$ was the plain strain modulus $\left(E^{*} \frac{E}{1-v^{2}}\right)$. The true hardness has been calculated based on this equation.

The work of indentation has also been obtained from the loading and unloading curves. The total work of indentation $\left(W_{\text {tot }}\right)$ is defined as the area under the loading curve, the reversible work $\left(\mathrm{W}_{\mathcal{u}}\right)$ as the area under the unloading curve and the irreversible work $\left(\mathrm{W}_{p}\right)$ as the area enclosed by the loading and unloading curve.

\subsection{Fourier transform infrared microspectroscopy}

FTIRM was performed on $30 \times 30 \mu \mathrm{m}^{2}$ area on 55 BSUs tested with instrumented indentation (Fig. 2(A)). The cutting 
A

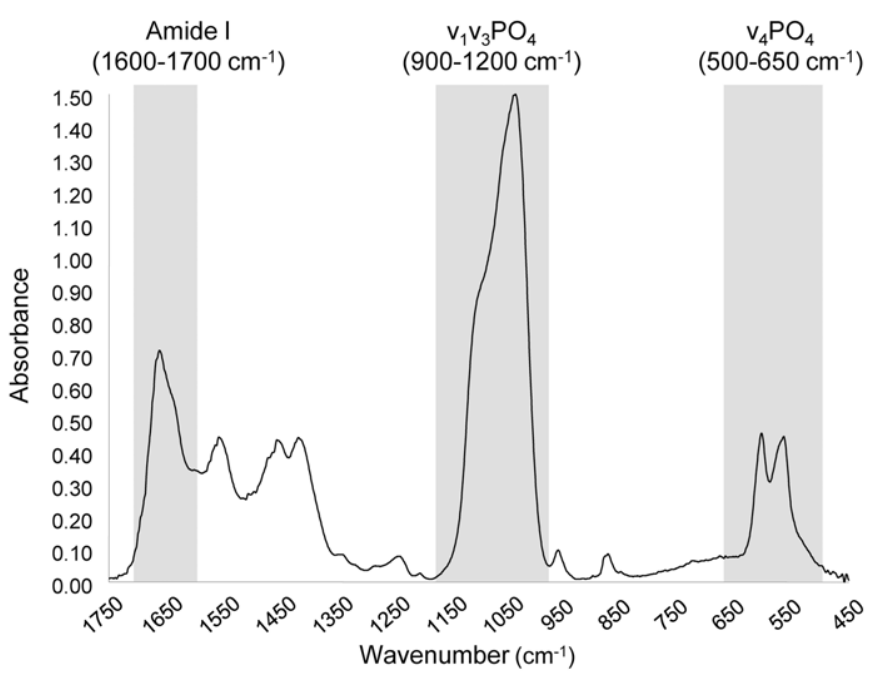

$\mathrm{B}_{0.50} \quad \mathrm{v}_{4} \mathrm{PO}_{4}\left(500-650 \mathrm{~cm}^{-1}\right)$

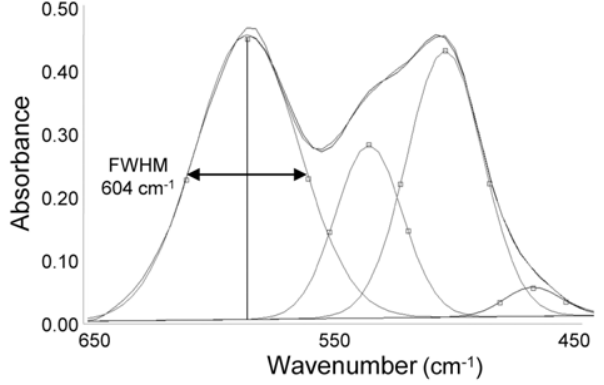

$C_{0.80 \quad \text { Amide I }\left(1600-1700 \mathrm{~cm}^{-1}\right)}$

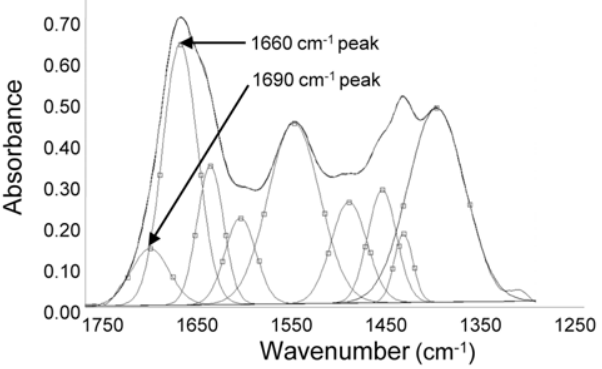

Fig. 2 - Infrared spectra of a $30 \mu \mathrm{m} \times 30 \mu \mathrm{m}$ area assessed on a cortical bone structural unit (A). Detail of the calculation of the crystallinity index defined by the full width at half maximum (FWHM) of $604 \mathrm{~cm}^{-1}$ peak is given in (B). (C) represents the deconvoluted peaks allowing to deduce the collagen maturity $\left(1660 / 1690 \mathrm{~cm}^{-1}\right.$ area peak ratio).

of the $100 \mu \mathrm{m}$-thick sections into $2 \mu \mathrm{m}$-thick ones led to a loss of material, explaining the fact that only 55 BSUs were analyzed by FTIRM (among the 150 tested with indentation). The collection of spectra was performed in transmission mode with a Spectrum 100 spectrometer equipped with an Auto-IMAGE microscope (Perkin-Elmer, Shelton, Connecticut, USA). Each spectrum corresponded to 150 cumulated scans. The contributions of air and MMA were subtracted from the individual spectra, and a baseline correction and normalization at absorbance 1.5 on the $v_{3} \mathrm{PO}_{4}$ were done. The spectra were then curve-fitted using GRAMS/AI software (Thermo galactic, Salem, New Hampshire, USA) to analyze the peaks $v_{4} \mathrm{PO}_{4}\left(500-650 \mathrm{~cm}^{-1}\right)$ and amides I $\left(1600-1700 \mathrm{~cm}^{-1}\right)$. The mineral crystallinity index was measured as the FWHM of the $604 \mathrm{~cm}^{-1}$ band in the $v_{4} \mathrm{PO}_{4}$ domain (Fig. 2(B)). Inversely proportional to the FWHM of the peak at $604 \mathrm{~cm}^{-1}$, the mineral crystallinity index reflected both the crystal size and how well the ions of the crystal were ordered in the unit cells, that is, the perfection and extent of the ordered disposition of the individual ions in the crystal (Farlay et al., 2010). Collagen maturity was evaluated by the area ratio $1660 \mathrm{~cm}^{-1}$ over $1690 \mathrm{~cm}^{-1}$ peaks (Fig. 2(C)).

\subsection{Statistical analysis}

Statistical analysis was performed under SPSS v16.0 (SPSS inc., Chicago Illinois, USA) using an alpha risk set at $5 \%$. Results were reported as mean \pm standard deviation (SD). The distribution of the variables was tested with the Shapiro-Wilk procedure. All variables were normally distributed and a parametric approach was used. The influence of the microstructure on the micromechanical behavior was studied using linear regression analyses ( $r$ corresponds to Pearson's correlation coefficient). To explain how micromechanical variables are affected by those reflecting mineral and organic matrix, stepwise forward multiple regression models including partial correlations were used. Values of $\beta$ correspond to the standardized regression coefficient if the predictor enters the equation at the next step of the stepwise analysis.

\section{Results}

3.1. Role of tissue mineral density in micromechanical properties of cortical bone

A total of 150 cortical osteons and interstitial fragments were identified from the microradiographs, based on a large range of DMB (Fig. 3). Mean DMB was $1.13 \pm 0.09 \mathrm{~g} / \mathrm{cm}^{3}$. Micromechanical variables deduced from load-displacement curves measured on the same 150 BSUs were $19.41 \pm$ $2.70 \mathrm{GPa}, 0.63 \pm 0.11 \mathrm{GPa}$ and $1.81 \pm 0.39 \mathrm{GPa}$ for $E, H_{C}$ and $H$, respectively (Table 1 ).

Linear regression revealed strong and positive correlations between DMB and micromechanical variables (Fig. 4). DMB was significantly correlated with $E(r=0.64, p<0.0001), H_{c}(r=$ $0.79, p<0.0001)$ and $\mathrm{H}(r=0.74, p<0.0001)$. E reflecting elastic behavior was strongly correlated with $H_{C}(r=0.79, p<$ $0.0001)$ and also more moderately with $\mathrm{H}(r=0.59, p<$ 0.005), reflecting a purely plastic hardness (Fig. 5). The ratio of irreversible work to total work for a complete loading-unloading cycle ([ $\left.\left.\mathrm{W}_{\text {tot }}-\mathrm{W}_{\mathrm{u}}\right] / \mathrm{W}_{\text {tot }}\right)$ was strongly correlated to the ratio $H / E^{*}(r=0.92, p<0.001)$ (Fig. 6). 


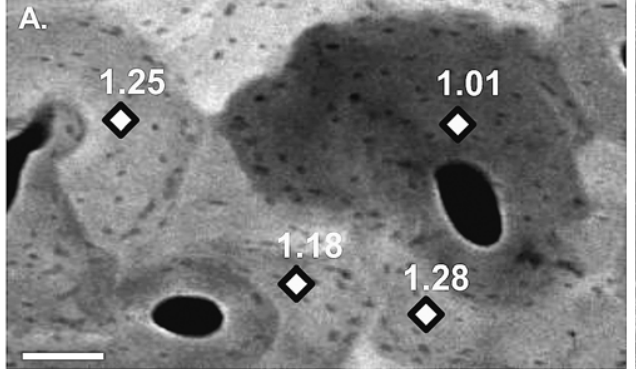

DMB values in $\mathbf{g} / \mathrm{cm}^{3}$

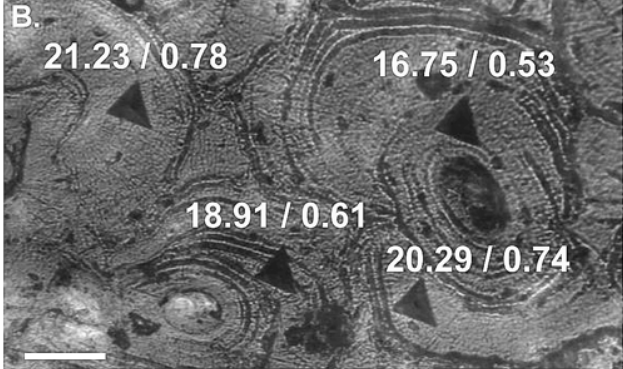

E / Hc values in GPa

Fig. 3 - Degree of mineralization of bone (DMB) measured on a microradiograph illustrating various cortical bone structural units (A). (B) Indents left at bone surface on the same region of interest and values obtained for elastic modulus (E) and contact hardness $\left(H_{C}\right)$, respectively. Bar scale: $50 \mu \mathrm{m}$.
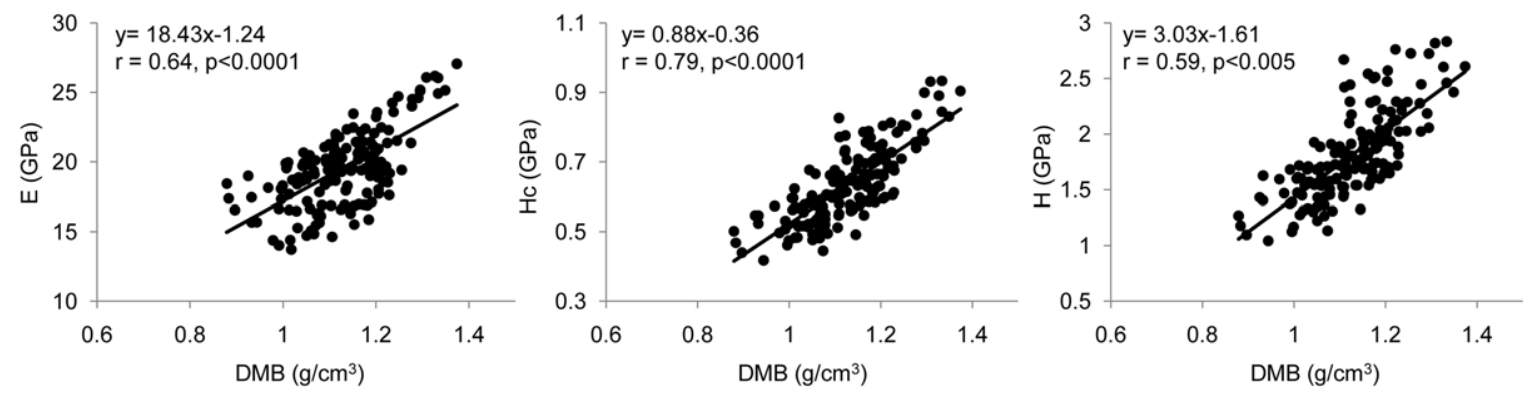

Fig. 4 - Correlations obtained between the degree of mineralization of bone (DMB) and the micromechanical properties: elastic modulus $(E)$, contact hardness $(H)$ and true hardness $(H)$. These linear regression plots show the strong influence of mineral content in mechanical behavior of bone at the bone structural unit level of organization.

Table 1 - Mean values and standard deviation (SD) for degree of mineralization (DMB), elastic modulus (E), contact hardness $\left(H_{C}\right)$, true hardness $(H)$, collagen maturity and crystallinity index measured at bone structural unit (BSU) level.

\begin{tabular}{|c|c|c|c|c|c|}
\hline \multicolumn{2}{|c|}{ Variables } & \multirow[t]{2}{*}{ Mean } & \multirow[t]{2}{*}{ SD } & \multicolumn{2}{|c|}{ Range } \\
\hline & & & & Minimum & Maximum \\
\hline \multirow[t]{4}{*}{ Whole population of BSUs $(n=150)$} & $\operatorname{DMB}\left(\mathrm{g} / \mathrm{cm}^{3}\right)$ & 1.13 & 0.09 & 0.88 & 1.37 \\
\hline & $E(\mathrm{GPa})$ & 19.41 & 2.70 & 13.64 & 26.62 \\
\hline & $\mathrm{H}_{\mathrm{C}}(\mathrm{GPa})$ & 0.63 & 0.11 & 0.42 & 0.93 \\
\hline & $\mathrm{H}(\mathrm{GPa})$ & 1.81 & 0.39 & 1.04 & 2.83 \\
\hline \multirow[t]{6}{*}{ BSUs analyzed in FTIRM $(n=55)$} & $\mathrm{DMB}\left(\mathrm{g} / \mathrm{cm}^{3}\right)$ & 1.10 & 0.08 & 0.93 & 1.29 \\
\hline & Crystallinity index & 24.79 & 0.70 & 22.85 & 26.09 \\
\hline & Collagen maturity & 4.69 & 0.76 & 2.78 & 5.99 \\
\hline & $E(\mathrm{GPa})$ & 18.49 & 2.58 & 13.94 & 24.25 \\
\hline & $\mathrm{H}_{\mathrm{C}}(\mathrm{GPa})$ & 0.63 & 0.09 & 0.48 & 0.84 \\
\hline & $\mathrm{H}(\mathrm{GPa})$ & 1.81 & 0.34 & 1.22 & 2.67 \\
\hline
\end{tabular}

3.2. Role of mineral and collagen quality in micromechanical behavior

Due to technical limitations, 55 of the 150 indented BSUs were also analyzed by FTIRM. Crystallinity index and collagen maturity were $24.7 \pm 0.7$ and $4.7 \pm 0.8$, respectively (Table 1 ). Linear regression analysis demonstrated a moderate positive correlation between collagen maturity and $E(r=0.39, p<$ 0.0001 ) and a positive correlation between collagen maturity and $H_{C}$ and $H(r=0.59$ and $r=0.58$, respectively, $p<0.0001)$. However, the crystallinity index was not correlated with any of the mechanical parameter $E, H_{C}$ and $H(r=0.15, r=0.25$ and $r=0.25$, respectively, $p>0.05$ ).

\subsection{Multiple regression analysis}

This statistical analysis was performed on the 55 BSUs in which all parameters were measured. Three stepwise regression analyses were performed using one of the mechanical parameters $\left(E, H_{C}\right.$ or $H$ ) as dependent variable and the structural parameters (DMB, collagen maturity and crystallinity index) as independent variables. Depending on these results, a multiple regression analysis was performed using the same dependent variables but only with the independent variables that were significant in the stepwise regression model. The multiple regression analysis gave the associated part correlation for each independent variable and the final correlation coefficient of the model (Table 2). In this 
Table 2 - Multiple regression analysis describing micromechanical variables (elastic modulus $(E)$, contact hardness $\left(H_{C}\right)$ and true hardness $(\mathrm{H})$ ) as a function of the degree of mineralization of bone (DMB), collagen maturity and crystallinity index. Results highlight the importance of mineral in elastic behavior of bone tissue while collagen maturity is related to plastic deformation.

\begin{tabular}{|c|c|c|c|c|c|}
\hline \multicolumn{2}{|r|}{ Variables } & & \multirow[t]{2}{*}{ Final $R$} & \multirow[t]{2}{*}{ Part correlation $(\beta)$} & \multirow[t]{2}{*}{$p$-value } \\
\hline & Indepen & & & & \\
\hline \multirow[t]{3}{*}{$E$} & $\mathrm{DMB}$ & 1 & & 0.68 & $<0.001$ \\
\hline & Collagen maturity & Out & 0.68 & - & - \\
\hline & Crystallinity index & Out & & - & - \\
\hline \multirow[t]{3}{*}{$\mathrm{H}_{\mathrm{C}}$} & $\mathrm{DMB}$ & 1 & & 0.46 & $<0.001$ \\
\hline & Collagen maturity & 2 & 0.74 & 0.33 & 0.004 \\
\hline & Crystallinity index & Out & & - & - \\
\hline \multirow[t]{3}{*}{$\mathrm{H}$} & $\mathrm{DMB}$ & Out & & - & - \\
\hline & Collagen maturity & 1 & 0.58 & 0.58 & $<0.001$ \\
\hline & Crystallinity index & Out & & - & - \\
\hline
\end{tabular}
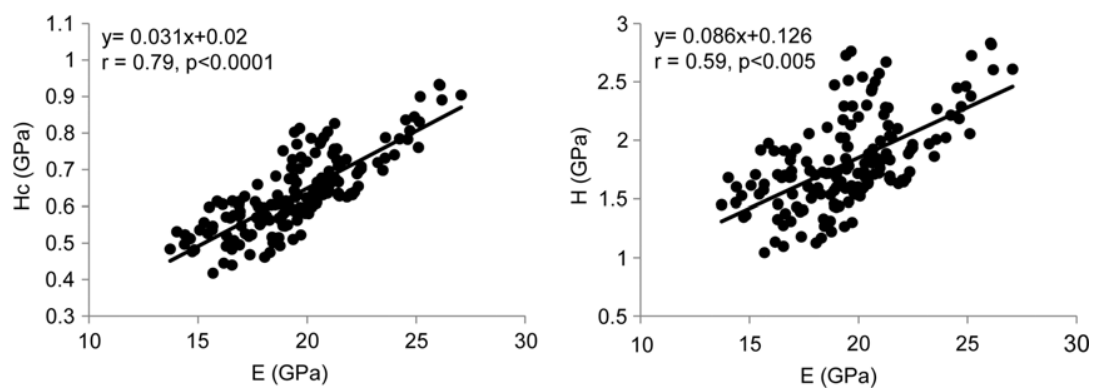

Fig. 5 - Significant relationship obtained between contact hardness $\left(H_{c}\right)$, true hardness $(H)$ and elastic modulus $(E)$. Those plots show the strong linear dependence of $H_{C}$ with elastic properties whereas $\mathrm{H}$, reflecting plastic deformation is moderately linked to $E$.

analysis, $E$ was correlated only with $\operatorname{DMB}(\beta=0.68, p<$ $0.001), H_{C}$ was correlated with both DMB $(\beta=0.46, p<0.001)$ and collagen maturity $(\beta=0.33, p=0.004)$, and $H$ was only correlated with collagen maturity $(\beta=0.58, p<0.001)$ (Table 2).

\section{Discussion}

\subsection{Correlation between mechanical and microstructural variables}

In this study, the relationships between bone components and their micromechanical behavior were examined at the level of cortical BSUs in postmenopausal osteoporotic women. The statistical model used was based on three independent parameters of bone ultrastructure reflecting mineral quantity (DMB), mineral quality (crystallinity index) and the age of collagen matrix (collagen maturity). These variables are the minimal ones required to define the microstructure of bone tissue, and are likely to be the best predictor of bone mechanical properties at osteon level. The results of micromechanical properties $\left(E, H\right.$ and $H_{C}$ ), DMB and ultrastructural variables (crystallinity index and collagen maturity) were consistent with previous studies (Boivin et al., 2008; Farlay et al., 2010; Hengsberger et al., 2002; Hoffler et al., 2005; Paschalis et al., 1996; Smith et al., 2010; Zysset, 2009). It is known that elastic deformation is related to the mineral but, to our knowledge, this study is the first to clearly establish a link between plastic deformation and collagen at the osteon level.

Indentation tests were performed at relatively high load/depth in order to avoid lamellae heterogeneity. Even if it has been proven that mechanical properties are different from one lamella to another in a single osteon (Fratzl and Weinkamer, 2007; Hengsberger et al., 2002), this choice was made for several reasons. First, at lamella level, measurements are sensitive to surface roughness and to potential mechanical alteration due to surface preparation; by indenting several lamellae simultaneously, those risks of error were reduced. Furthermore, if one orientation of the lamellae is favored when testing bone at lamella level, there is a risk of overestimating the mechanical behavior of bone tissue. Due to a rotated plywood-like structure (Ascenzi and Bonucci, 1968; Giraudguille, 1988; Weiner et al., 1999) and/or variation in collagen and mineral density between successive lamellae (Marotti et al., 1993), osteon lamellar structure is periodic along its diameter. Considering one orientation of the lamellae, the mechanical properties do not vary significantly across the osteon (Burket et al., 2011; Hengsberger et al., 2001). Thus, indentation of several lamellae allowed an average measurement of the mechanical response of bone tissue. Roughness measurements made by atomic force microscopy on similar bone sections showed a mean variation of $200 \mathrm{~nm}$ in a single osteon (data not shown). Therefore, indentation tests were performed with 


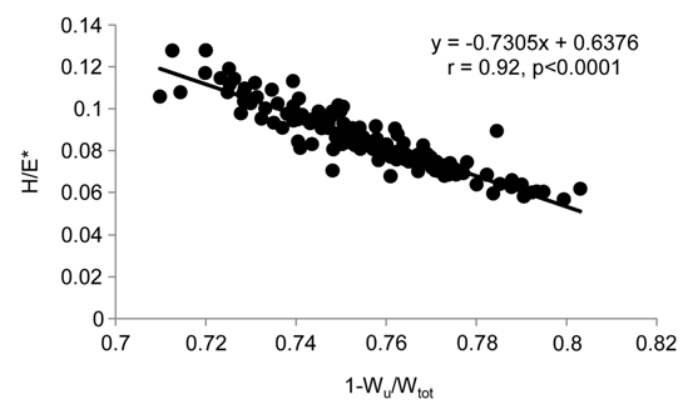

Fig. 6 - Regression plot of $\mathrm{H} / \mathrm{E}^{*}$ versus the ratio of irreversible work to total work for a complete loading-unloading cycle $\left(\left[\mathrm{W}_{\text {tot }}-\mathrm{W}_{u}\right] / \mathrm{W}_{\text {tot }}\right)$.

a depth of $5 \mu \mathrm{m}$ in order to exceed by 20 times the mean roughness (norm ISO 14577-4) and to indent simultaneously 4-6 lamellae. Continuous stiffness measurements were done to testify of the homogeneity of the BSU along its depth.

According to Hertz's contact theory, the mechanical properties measured by nanoindentation concern a semiellipsoidal volume extending to about nine times the indentation depth in vertical direction and about seven times the depth in radial direction (Hengsberger et al., 2002; Johnson, 1985). For an indentation depth of $5 \mu \mathrm{m}$, this represents a volume of $45 \mu \mathrm{m}$ in depth and $35 \mu \mathrm{m}$ in the lateral direction. The first value was consistent with the length of osteon structure and with the thickness of bone section $(100 \pm 1 \mu \mathrm{m})$. Thus, indents positions were chosen to match the lateral deformation as best as possible. Moreover, indent locations were also chosen at sites distant from visible lacunae or other discontinuities in order to better satisfy the continuum assumption.

Since $E$ and $H_{C}$ were strongly correlated, the model developed by Sakai was used to obtain a purely plastic variable $H$ (Oyen, 2006; Sakai, 1999). Unlike Smith et al. (2010), we found a moderate correlation between $E$ and $H$. This correlation could be explained by a larger range in DMB. Since both DMB and collagen maturity are determined by common factors (i.e., time since deposition, mineral apposition rate), these parameters evolve jointly, explaining the moderate correlation between them. Besides, elastic deformation $(E)$ was mainly described by DMB and plastic deformation $(\mathrm{H})$ was mainly explained by collagen maturity. Therefore, a moderate correlation between $E$ and $H$ seems to be legitimate. Correlations between mineral quantity (DMB) and micromechanical variables $\left(E, H_{C}\right.$ and $\left.H\right)$ were consistent with other studies made at nano-, micro- and macro- scales (Boivin et al., 2008; Burket et al., 2011; Hoc et al., 2006; Mulder et al., 2008; Smith et al., 2010). Since elastic modulus is mainly explained by mineral density, its heterogeneity is mainly due to the distribution of BSU as their mineral composition is rather homogeneous (Smith et al., 2010). Besides, the strong correlation between the ratio of irreversible work to total work for a complete loading-unloading cycle $\left(\left[\mathrm{W}_{\text {tot }}-\mathrm{W}_{\mathrm{u}}\right] / \mathrm{W}_{\text {tot }}\right)$ and the ratio $H / E^{*}$ is in agreement with previous work (Cheng and Cheng, 1998).

\subsection{Influence of collagen maturity}

Collagen matrix maturity was more linked to plastic deformation $(H)$ than with elastic deformation $(E)$. This was consistent with the recent findings of Boivin et al. (2008) concluding from their observations in human iliac bone that osteoid tissue represented about one third of the $H_{C}$ of mineralized matrix. Besides, in Osteogenesis imperfecta (OI), a disease associated with an altered collagen structure, an increase in brittleness of bone tissue has been reported. Since collagen alone has a reduced strength, this suggests that the reduction in post-yield behavior of bone in OI arises directly from changes in organic matrix (Fratzl et al., 2004). Since, Fratzl et al. (2004) have suggested that as hydroxyapatite is a rigid material not capable of dissipating much energy, collagen would play a key role in bone toughness. However, a single type I collagen fibril has a quasi perfectly-elastic tensile behavior, or a viscoelastic behavior in hydrated state (Svensson et al., 2010; van der Rijt et al., 2006). These results suggested that the association between mineral and organic matrix, two mostly elastic components, needs to be considered to understand the complex visco-elasto-plastic behavior of bone matrix (Oyen and Cook, 2009; Oyen and Ko, 2007; Launey et al., 2010).

Even though the deformation mechanisms of bone at micro- and nanoscale remain unclear, several hypotheses have been proposed. Many studies revealed that collagen network integrity and crosslinking is implied in the ability to absorb energy and undergo deformation after yielding at various levels of the structural hierarchy (Reilly and Burstein, 1975; Thompson et al., 2001; Wang et al., 2002; Zioupos et al., 1999). Fantner et al. (2005) suggested that collagen fibrils are held together by a non-fibrillar organic matrix acting as a glue and may be partially responsible for the bone toughness. Following this model, Gupta et al. (2005) suggested that shearing occurs in the interfibrillar thin matrix layers. When the glue is sheared, energy is dissipated in the glue (through rupture of sacrificial bonds). Even if this model was presented for tensile deformation, the same mechanism seems consistent in compression and could support the results of this study.

Using nanoindentation on demineralized bovine cortical bone, Tai et al. (2005) observed that collagen fibrils lost their supramolecular banding structure close to the junction edge of the faces of the indenter, corresponding to regions where plastic deformations obtained from FEA simulation were maximal. In parallel, there is also evidence showing the role of collagen maturity in the time-dependent deformation of bone under loading, (i.e., the viscous and viscoelastic behavior) during indentation testing (Isaksson et al., 2010). These results highlight the major and complex impact of collagen maturity in the viscoplastic behavior of bone matrix.

\subsection{Influence of the crystallinity of the mineral phase}

Recently, Yerramshetty and Akkus (2008) showed that the crystallinity (i.e., the size and the stoechiometry of apatite crystals) is an important variable in the macromechanical behavior of human cortical bone. Indeed, combination of Raman spectroscopy to assess the crystallinity and monotonic and fatigue tension tests, revealed that crystallinity may explain 7 to $48 \%$ of the monotonic and $11 \%-64 \%$ of fatigue mechanical properties in human femoral cortical bone. Surprisingly, our data did not show correlations between crystallinity 
index and micromechanical properties determined using indentation testing. This could reflect that mechanical behavior is differently modulated by structural variables at BSU and tissue levels. Also, this latter work was done in tensile conditions and in a healthy loaded bone, limiting the comparison with our study where the results should be considered only for indentation loading along the transversal direction of BSUs (Yerramshetty and Akkus, 2008). Postmenopausal osteoporosis involves a high level of bone remodeling Recker et al. (2004). At BSU level, osteoporosis leads to changes in the distribution of mineral and organic contents and quality variables as it acts on the probability for a given osteon to be resorbed before its complete maturation (Boivin et al., 2009). A previous study of the mineralization time course at BSU level in ewes has revealed that crystallinity did not increase linearly with time, while DMB and $H_{c}$, which were positively correlated $\left(R^{2}=0.52, p<0.0001\right)$, did. Furthermore, in this latter study, crystallinity significantly increased first during primary mineralization, then a second time after 18 months of mineralization, when $\mathrm{DMB}$ and $\mathrm{H}_{\mathrm{C}}$ reached their physiological upper limit (Bala et al., 2010). Present results are consistent with this dissociation between mineral quantity, mineral crystallinity and micromechanics properties at BSU level. This suggests that the mean crystallinity, which depends on the mean tissue age (influenced by remodeling activity), plays a role in whole bone strength (Yerramshetty and Akkus, 2008). In contrast at the BSU level, micromechanical properties are mostly related to mineral content and collagen matrix maturity.

\subsection{Limitations}

The sample preparation is the main limitation of this study. Bone biopsies were prepared for a prior histological study. First, dehydration in alcohol is known to increase by $10 \%$ the hardness and by $15 \%-20 \%$ the elastic modulus (Bushby et al., 2004; Dall'Ara et al., 2007; Donnelly et al., 2006). Second, the embedding in MMA with preliminary infusion increases substantially the properties measured using indentation (Bushby et al., 2004). However, as all samples were prepared following the same protocol, this should not affect comparative trends. Moreover, the use of a prior dehydration and embedding is essential to enable the control of the experimental environment (Lewis and Nyman, 2008). From the infrared spectrum, the bands corresponding to MMA seemed to be more intense in young BSUs, suggesting a differential infusion of the resin depending on the DMB. We assume that the effects on the infrared results are minors as we corrected each spectrum by the MMA trace, but this could introduce some noise in the correlations between mechanical variables and FTIRM variables.

It would be interesting to repeat these experiments in an environment mimicking the physiologic one (constant controlled temperature, hydrated state). However, our experimental setup did not allow such analyses. Diez-Perez et al. (2010) have recently reported on an indentation technique in vivo, so-called 'reference point indentation (RPI)', allowing measurement of bone tissue toughness. Using this technology, the authors highlighted significant changes in micromechanical behavior between fractured and nonfractured patients (Diez-Perez et al., 2010). In vivo indentation is well adapted to test parameters reflecting the whole tissue mechanical behavior while our approach allows to mechanically test bone at structural unit level, formed during a bone remodeling cycle. To our knowledge, it is not possible to study such a level of organization with RPI, in vivo. It would be thus of interest to perform our analysis in similar patient groups on fresh samples, ex vivo (unembedded, hydrated) to study how our parameters could reflect the fracture risk as assessed with in vivo indentation testing.

Moreover, the values of indentation modulus assume an isotropic, elastic-plastic behavior of bone tissue with a defined Poisson's ratio $(v=0.3)$. Although it is known that bone tissue has a more complex behavior, unfortunately this technique requires such an assumption. Indeed, as observed during the $10 \mathrm{~s}$ holding segment from load-displacement curves, bone exhibits a viscous behavior. This has not been taken into account in our analysis but we believe this will not affect the trends highlighted in this study.

\section{Conclusions}

The combination of microradiography, Fourier transform infrared microspectroscopy and nanoindentation is a valuable tool to characterize, at BSU level, both the micromechanical properties and the quality of mineral and organic components of bone matrix. In cortical bone from patients suffering from postmenopausal osteoporosis, interactions between mechanical parameters reflecting elastic and plastic deformations and a multiscale definition of matrix quality were obtained. This model supported the idea of a link between elastic properties and mineral content and between plastic behavior and collagen maturity at osteon level.

\section{Acknowledgments}

The authors gratefully acknowledge Dr. Delphine Farlay for helpful discussions and comments during the preparation of the manuscript; and Anne-Sophie Bravo Martin for her technical expertise and assistance.

\section{R E F E R E N C E S}

Amprino, R., 1958. Investigations on some physical properties of bone tissue. Acta Anat. 34, 161-186.

Ascenzi, A., Bonucci, E., 1968. The compressive properties of single osteons. Anat. Rec. 161, 377-391.

Bala, Y., Farlay, D., Delmas, P.D., Meunier, P.J., Boivin, G., 2010. Time sequence of secondary mineralization and microhardness in cortical and cancellous bone from ewes. Bone 46, 1204-1212.

Boivin, G., Bala, Y., Doublier, A., Farlay, D., Ste-Marie, L.G., Meunier, P.J., Delmas, P.D., 2008. The role of mineralization and organic matrix in the microhardness of bone tissue from controls and osteoporotic patients. Bone 43, 532-538.

Boivin, G., Farlay, D., Bala, Y., Doublier, A., Meunier, P.J., Delmas, P.D., 2009. Influence of remodeling on the mineralization of bone tissue. Osteoporosis Int. 20, 1023-1026. 
Boivin, G., Meunier, P.J., 2002. The degree of mineralization of bone tissue measured by computerized quantitative contact microradiography. Calcif. Tissue Int. 70, 503-511.

Burket, J., Gourion-Arsiquaud, S., Havill, L.M., Baker, S.P., Boskey, A.L., van der Meulen, M.C.H., 2011. Microstructure and nanomechanical properties in osteons relate to tissue and animal age. J. Biomech. 44, 277-284.

Bushby, A.J., Ferguson, V.L., Boyde, A., 2004. Nanoindentation of bone: comparison of specimens tested in liquid and embedded in polymethymetacrylate. J. Mater. Res. 19, 249-259.

Carden, A., Morris, M.D., 2000. Application of vibrational spectroscopy to the study of mineralized tissues (review) J. Biomed. Opt. 5, 259-268.

Carlstrom, D., 1954. Micro-hardness measurements on single haversian systems in bone. Experientia 10, 171-172.

Cheng, Y.-T., Cheng, C.-M., 1998. Relationships between hardness, elastic modulus, and the work of indentation. Appl. Phys. Lett. 73, 614-616.

Cowin, S.C., 2001. Bone Mechanics Handbook, 2nd ed. CRC Press LLC, Boca Raton, FL.

Currey, J.D., 2003. Role of collagen and other organics in the mechanical properties of bone. Osteoporosis Int. 14, S29-S36.

Dall'Ara, E., Ohman, C., Baleani, M., Viceconti, M., 2007. The effect of tissue condition and applied load on Vickers hardness of human trabecular bone. J. Biomech. 40, 3267-3270.

Diez-Perez, A., Güerri, R., Nogues, X., Cáceres, E., Pena, M.J., Mellibovsky, L., Randall, C., Bridges, D., Weaver, J.C., Proctor, A., Brimer, D., Koester, K.J., Ritchie, R.O., Hansma, P.K., 2010. Microindentation for in vivo measurement of bone tissue mechanical properties in humans. J. Bone Miner. Res. 25, 1877-1885.

Donnelly, E., Baker, S.P., Boskey, A.L., van der Meulen, M.C., 2006. Effects of surface roughness and maximum load on the mechanical properties of cancellous bone measured by nanoindentation. J. Mater. Res. Part A 77, 426-435.

Evans, G.P., Behiri, J.C., Currey, J.D., Bonfield, W., 1990. Microhardness and Young's modulus in cortical bone exhibiting a wide range of mineral volume fractions, and in bone analogue. J. Mater. Sci. Mater. Med. 1, 38-43.

Fantner, G.E., Hassenkam, T., Kindt, J.H., Weaver, J.C., Birkedal, H., Pechenik, L., Cutroni, J.A., Cidade, G.A.G., Stucky, G.D., Morse, D.E., Hansma, P.K., 2005. Sacrificial bonds and hidden length dissipate energy as mineralized fibrils separate during bone fracture. Nat. Mater. 4, 612-616.

Farlay, D., Panczer, G., Rey, C., Delmas, P.D., Boivin, G., 2010. Mineral maturity and crystallinity index are distinct characteristics of bone mineral. J. Bone Miner. Metab. 28, 433-445.

Ferguson, V.L., 2009. Deformation partitioning provides insight into elastic, plastic, and viscous contributions to bone material behavior. J. Mech. Behav. Biomed. Mater. 2, 364-374.

Follet, H., Boivin, G., Rumelhart, C., Meunier, P.J., 2004. The degree of mineralization is a determinant of bone strength: a study on human calcanei. Bone 34, 783-789.

Fratzl, P., Gupta, H.S., Paschalis, E.P., Roschger, P., 2004. Structure and mechanical quality of the collagen-mineral nanocomposite in bone. J. Mater. Chem. 14, 2115-2123.

Fratzl, P., Weinkamer, R., 2007. Nature's hierarchical materials. Prog. Mater. Sci. 52, 1263-1334.

Giraudguille, M.M., 1988. Twisted plywood architecture of collagen fibrils in human compact-bone osteons. Calcif. Tissue Int. 42, 167-180.

Gupta, H.S., Wagermaier, W., Zickler, G.A., Aroush, D.R.B., Funari, S.S., Roschger, P., Wagner, H.D., Fratzl, P., 2005. Nanoscale deformation mechanisms in bone. Nano Lett. 5, 2108-2111.

Hadjidakis, D.J., Androulakis II, , 2006. Bone remodeling. Ann. New York Acad. Sci. 1092, 385-396.
Hengsberger, S., Kulik, A., Zysset, P., 2001. A combined atomic force microscopy and nanoindentation technique to investigate the elastic properties of bone structural units. Eur. Cells Mater. 1, 12-17.

Hengsberger, S., Kulik, A., Zysset, P., 2002. Nanoindentation discriminates the elastic properties of individual human bone lamellae under dry and physiological conditions. Bone 30, 178-184.

Hoc, T., Henry, L., Verdier, M., Aubry, D., Sedel, L., Meunier, A., 2006. Effect of microstructure on the mechanical properties of Haversian cortical bone. Bone 38, 466-474.

Hodgskinson, R., Currey, J.D., Evans, G.P., 1989. Hardness, an indicator of the mechanical competence of cancellous bone. J. Orthop. Res. 7, 754-758.

Hoffler, C.E., Guo, X.E., Zysset, P.K., Goldstein, S.A., 2005. An application of nanoindentation technique to measure bone tissue Lamellae properties. J. Biomech. Eng. 127, 1046-1053.

Isaksson, H., Malkiewicz, M., Nowak, R., Helminen, H.J., Jurvelin, J.S., 2010. Rabbit cortical bone tissue increases its elastic stiffness but becomes less viscoelastic with age. Bone 47, 1030-1038.

Johnson, K.L., 1985. Normal Contact of Elastic Solids: Hertz Theory, Contact Mechanics. Cambridge University Press, Cambridge, UK.

Landis, W.J., 1995. The strength of a calcified tissue depends in part on the molecular structure and organization of its constituent mineral crystals in their organic matrix. Bone 16, 533-544.

Launey, M.E., Buehler, M.J., Ritchie, R.O., 2010. On the mechanistic origins of toughness in bone. Annu. Rev. Mater. Res. 40, 25-53.

Lewis, G., Nyman, J.S., 2008. The use of nanoindentation for characterizing the properties of mineralized hard tissues: state-of-the art review. J. Biomed. Mater. Res. Part B 87, 286-301.

Marotti, G., Lees, , Reeve, , 1993. A new theory of bone lamellation. Calcif. Tissue Int. 53, S47-S56.

Mulder, L., Koolstra, J.H., den Toonder, J.M.J., van Eijden, T., 2008. Relationship between tissue stiffness and degree of mineralization of developing trabecular bone. J. Biomed. Mater. Res. Part A 84A, 508-515.

Oliver, W.C., Pharr, G.M., 1992. An improved technique for determining hardness and elastic modulus. J. Mater. Res. 7, 1564-1583.

Oyen, M.L., 2006. Nanoindentation hardness of mineralized tissues. J. Biomech. 39, 2699-2702.

Oyen, M.L., Cook, R.F., 2003. Load-displacement behavior during sharp indentation of viscous-elastic-plastic materials. J. Mater. Res. 18, 139-150.

Oyen, M.L., Cook, R.F., 2009. A practical guide for analysis of nanoindentation data. J. Mech. Behav. Biomed. Mater. 2, 396-407.

Oyen, M.L., Ko, C.C., 2007. Examination of local variations in viscous, elastic, and plastic indentation responses in healing bone. J. Mater. Sci. Mater. Med. 18, 623-628.

Paschalis, E.P., DiCarlo, E., Betts, F., Sherman, P., Mendelsohn, R., Boskey, A.L., 1996. FTIR microspectroscopic analysis of human osteonal bone. Calcif. Tissue Int. 59, 480-487.

Recker, R., Lappe, J., Davies, K., Heaney, R., 2004. Bone remodeling increases substantially in the years after menopause and remains increased in older osteoporosis patients. J. Bone Miner. Res. 19, 1628-1633.

Reilly, D.T., Burstein, A.H., 1975. The elastic and ultimate properties of compact bone tissue. J. Biomech. 8, 393-405.

Rho, J.Y., Kuhn-Spearing, L., Zioupos, P., 1998. Mechanical properties and the hierarchical structure of bone. Med. Eng. Phys. 20, 92-102.

Roschger, P., Paschalis, E.P., Fratzl, P., Klaushofer, K., 2008. Bone mineralization density distribution in health and disease. Bone 42, 456-466. 
Sakai, M., 1999. The Meyer hardness: a measure for plasticity. J. Mater. Res. 14, 3630-3639.

Smith, L.J., Schirer, J.P., Fazzalari, N.L., 2010. The role of mineral content in determining the micromechanical properties of discrete trabecular bone remodeling packets. J. Biomech. 43, 3144-3149.

Svensson, R.B., Hassenkam, T., Hansen, P., Magnusson, S.P., 2010. Viscoelastic behavior of discrete human collagen fibrils. J. Mech. Behav. Biomed. Mater. 3, 112-115.

Tai, K., Qi, H.J., Ortiz, C., 2005. Effect of mineral content on the nanoindentation properties and nanoscale deformation mechanisms of bovine tibial cortical bone. J. Mater. Sci. Mater. Med. 16, 947-959.

Thompson, J.B., Kindt, J.H., Drake, B., Hansma, H.G., Morse, D.E., Hansma, P.K., 2001. Bone indentation recovery time correlates with bond reforming time. Nature 414, 773-776.

van der Rijt, J.A., van der Werf, K.O., Bennink, M.L., Dijkstra, P.J., Feijen, J., 2006. Micromechanical testing of individual collagen fibrils. Macromol. Biosci. 6, 697-702.
Wang, X., Li, X., Bank, R.A., Agrawal, C.M., 2002. Effects of collagen unwinding and cleavage on the mechanical integrity of the collagen network in bone. Calcif. Tissue Int. 71, 186-192.

Weaver, J.K., 1966. The microscopic hardness of bone. J. Bone Joint Surg. Am. 48, 273-288.

Weiner, S., Traub, W., Wagner, H.D., 1999. Lamellar bone: structure-function relations. J. Struct. Biol. 126, 241-255.

Yerramshetty, J.S., Akkus, O., 2008. The associations between mineral crystallinity and the mechanical properties of human cortical bone. Bone 42, 476-482.

Zioupos, P., Currey, J.D., Hamer, A.J., 1999. The role of collagen in the declining mechanical properties of aging human cortical bone. J. Biomed. Mater. Res. 45, 108-116.

Zysset, P.K., 2009. Indentation of bone tissue: a short review. Osteoporosis Int. 20, 1049-1055.

Zysset, P.K., Guo, X.E., Hoffler, C.E., Moore, K.E., Goldstein, S.A., 1999. Elastic modulus and hardness of cortical and trabecular bone lamellae measured by nanoindentation in the human femur. J. Biomech. 32, 1005-1012. 